\title{
Correction to: Elevation of Pro-inflammatory and Anti-inflammatory Cytokines in Rat Serum after Acute Methamphetamine Treatment and Traumatic Brain Injury
}

\author{
Firas H. Kobeissy ${ }^{1,2,3} \cdot$ Zaynab Shakkour $^{1} \cdot$ Samer El Hayek ${ }^{4} \cdot$ Wael Mohamed $^{5,6} \cdot$ Mark S. Gold $^{7} \cdot$ Kevin K. W. Wang $^{2,3}$ \\ Accepted: 11 October 2021 / Published online: 7 November 2021 \\ (c) Springer Science+Business Media, LLC, part of Springer Nature 2021
}

\section{Correction to: Journal of Molecular Neuroscience (2021) https://doi.org/10.1007/s12031-021-01886-8}

Publisher's Note Springer Nature remains neutral with regard to jurisdictional claims in published maps and institutional affiliations.

The original version of this article, published on 20 September 2021, the authors have found an error. The fourth author family name is incorrect. Wael Mohammad should be "Wael Mohamed".

Original article has been corrected.

The original article can be found online at https://doi.org/10.1007/ s12031-021-01886-8.

Kevin K. W. Wang

kawangwang17@gmail.com

1 Department of Biochemistry and Molecular Genetics,

Faculty of Medicine, American University of Beirut, Beirut,

Lebanon

2 Program for Neurotrauma, Neuroproteomics, and Biomarkers Research, Gainesville, FL, USA

3 Department of Emergency Medicine, University of Florida, Gainesville, FL, USA

4 Department of Psychiatry, American University of Beirut, Beirut, Lebanon

5 Clinical Pharmacology Department, Menoufia Medical School, Menoufia University, Al Minufya, Egypt

6 Basic Medical Science Department, Kulliyyah of Medicine, International Islamic University Malaysia, Kuantan, Pahang, Malaysia

7 Washington University School of Medicine, Department of Psychiatry, and National Council, Washington University in St. Louis, Institute for Public Health, St. Louis, MO, USA 